\title{
Optimal Coordination of Overcurrent Relays in Radial System with Distributed Generation Using Modified Firefly Algorithm
}

\author{
Anang Tjahjono ${ }^{1,2}$, Dimas Okky Anggriawan ${ }^{1}$, Alfa Kusnal Faizin ${ }^{1}$, Ardyono Priyadi $^{1}$, \\ Margo Pujiantara ${ }^{1}$, and Mauridhi Hery Purnomo \\ Electrical Engineering Department ${ }^{1}$ Institut Teknologi Sepuluh Nopember \\ ${ }^{1,2}$ Politeknik Elektronika Negeri Surabaya \\ INDONESIA
}

\begin{abstract}
Overcurrent relays (OCRs) play a vital role in operating the protection of power distribution system. In the presence of distributed generation (DG), OCR coordination is used to ensure reliability and speed of relay operation to avoid unintentional DG disconnection during fault conditions. Therefore, this paper presents an optimal OCR coordination in radial system under the presence of DG. An optimal OCR coordination can be obtained by selecting time dial setting (TDS) and plug setting (PS). A modified firefly algorithm (MFA) is proposed to finds the optimal OCR coordination. The proposed method is applied to four different case studies with DG. The proposed method is compared to both the firefly algorithm (FA) and conventional method. The results show that the proposed method can significantly improve the result of the FA and reduce all cases operating time of the OCR coordination, which reaches $38.38 \%$.
\end{abstract}

\section{Introduction}

Protection coordination is important aspect to ensure continuity of electrical supply. Protection coordination requires analysis of load flow and short circuit for the protecting relay setting. Coordination schemes must ensure reliability, selectivity, flexibility and speed of relay operation to isolate the fault sections. OCRs are able to detect the fault conditions; and then, trip the circuit breaker $(\mathrm{CB})$ to disconnect the affected area of fault without bothering the other areas. OCRs use primary and backup protective devices [1]. The backup protective devices initiate to do the tripping if the primary protective devices fail to omit the fault. Good protection coordination can reduce impact of fault such as the spread of fault zones, unnecessary power blackouts and damage to equipment [2]. OCR characteristic, based on International Electrotechnical Commission (IEC), uses protection coordination such as normal inverse, very inverse and extremely inverse [3], [4], [5], [6].

Normally, OCR operates when it detects the over load current exceeding a preset value. The important variables to optimal coordination protection are the time setting multiplier (TSM) and plug setting multiplier (PSM). In the protection coordination, calculation the minimum fault current and the maximum load current determine Plug setting (PS) [1], [7], [8].

Distributed generation (DG) in power distribution system may cause several challenges in the power quality problems [9]. The significant problem is the possible loss of protection coordination. Moreover, impact of penetration DG changes short circuit fault levels, unintended islanding and false tripping in the network [10], [11]. New optimal coordination protection is required by considering the presence of DG to solve impact of penetration DG [12], [13]. There are many attempts to obtain the optimum TSM and PS settings such as conventional and heuristic techniques [14]. For conventional technique, OCRs coordination uses a trial-and-error approach. However, it has slow convergence rate because it requires a large number of iteration to achieve a suitable relay setting. Therefore, to overcome the problem of conventional techniques, the optimization techniques [15] are used. H. A. Abyaneh et al, proposed linear programming techniques to solve the OCR coordination problems [16],

Received: September $10^{\text {th }}, 2015$. Accepted: Desember $13^{\text {rd }}, 2015$

DOI: 10.15676/ijeei.2015.7.4.12 
[17]. A. Mahari et al [18], solved the OCR coordination problem using numerical algorithm. P. Bedekar et al [19], Used Big-M method to optimize time coordination of OCR in distribution system. Linear programming techniques have only single objective function is optimization so that this method is simple and easy to achieve convergence. However, linier programming techniques are not optimum answer [20]. Therefore, OCRs coordination problem is solved by using nature inspired algorithms (NIA) based on optimization method. C. W. So et al [21], proposed optimal OCRs coordination using evolutionary programming. F. Razavi et al [7], proposed genetic algorithm (GA) to solve OCRs coordination problem. P. P. Bedekar et al [22], proposed continuous genetic algorithm (CGA) implemented to improve GA in optimum coordination of OCR. Z. Moravej et al [23], used NSGA-II for optimal OCRs coordination. H. H. Zeineldin et al [24], used a modified particle swarm optimization for optimal coordination of OCRs. R. Thangaraj et al [25], optimized coordination of OCRs using modified differential evolution algorithms. M. Singh et al [26], implemented teaching learning- based optimization (TLBO) algorithm for optimal coordination of directional OCRs. P. P. Bedekar et al [27], used the hybrid GA-NLP for optimum coordination of direction OCRs. T. Amraee [28], proposed the seeker algorithm for coordination of directional OCRs.

Optimal OCRs using the FA is proposed by S.S. Gokhale [29]. However, FA requires long time to convergence. Therefore, in this paper, MFA is proposed to improve firefly algorithm (FA) in optimum coordination of OCRs [30], [31], [32]. To evaluate the algorithm, the four different cases in the radial network are proposed with the presence of DG [33].

In this paper, the organization includes introduction and some sections. Problem formulation of optimal OCRs coordination is explained in the section 2. FA is described in the section 3. The proposed algorithm is explained in the section 4 . In the section 5, simulation result and analysis of the proposed algorithm are used to optimize coordination of OCRs in the radial system with presence of DG. In the section 6, conclusion of this paper is described.

\section{Problem Formulation of Optimal OCRs coordination}

OCR important variables for optimum coordination are the time setting multiplier (TSM) and the plug setting (PS). TMS determines the operating time of the relay for optimum coordination of OCRs and PS influencing the relay operation. Therefore, TMS and PS are minimized by MFA to obtain the optimum coordination. The objective function (OF) shows an optimization problem, which it is obtained in eq. (1).

$$
\operatorname{Minimize}(O F)=\sum_{j=1}^{n} W_{j} \cdot t_{j, k}
$$

Where

$n=$ number of relays

$t_{j, k}=$ operating time of the relay $\mathrm{X}_{\mathrm{j}}$, for fault at $k$

$W_{j}=$ the weight which shows the probability of the occurrence of the fault on a line.

The value of weight is one, which fault occurrence has the same probability on each line. The total operating times of relays are reduced by minimizing their constraints as follows:

\section{A. Coordination Criteria}

Fault condition is sensed simultaneously by the primary and backup relays. The backup relay operates the tripping action when the primary relay fails to operate. The minimum operating time is determined by operating time of primary relay, operating time of circuit breaker (CB), the overshoot time. The coordination time interval (CTI) is the amount of time allowed between a primary device and its upstream backup. The coordination constraint can be stated as follow:

$$
t_{j, k}-t_{i, k} \geq \Delta t
$$


Where, $t_{j, k}$ is the operation time of the backup relay, for fault at $k . t_{i, k}$ is the operation time of the primary relay, for fault at $k . \Delta t$ is the coordination time interval with the value between 0.2 and $0.5 \mathrm{~s}[24]$.

\section{B. Bounds in Relay Operating Time}

Constraint happens on the operating time of OCRs because relays need minimum and maximum time to operate. Constraint can be stated as follow:

$$
t_{j, \min } \leq t_{j, k} \leq t_{j, \max }
$$

Where, $t_{j, \min }$ is minimum operating time of relay $j . t_{j, \max }$ is maximum operating time of relay $j$.

\section{Bounds on the TMS of each relay}

The TMS affects the operating time of relays in the optimum coordination. Therefore bound can be stated as follow:

$$
T M S_{j, \min } \leq T M S_{j} \leq T M S_{j, \max }
$$

Where, $T M S_{j, \min }$ is minimum value of TMS of relay $j . T M S_{j, \text { max }}$ is maximum value of TMS of relay $j$.

D. Bounds on PS of each relay

$$
P S_{j, \min } \leq P S_{j} \leq P S_{j, \max }
$$

Where, $P S_{j, \min }$ is minimum value of PS of relay $j . P S_{j, \max }$ is maximum value of PS of relay $j$.

\section{E. Bounds on relay characteristics}

In this paper, refers to IEC, OCRs have the characteristic with equations as follows:

$$
T_{j, m}=\frac{0.14 x \text { TMS }_{j}}{\left(\frac{I_{j, m}}{P S}\right)^{0.04}-1}
$$

Where, $I_{j, m}$ is the overcurrent which passing through the relay $j$.

\section{FA}

Xin She Yang proposes FA algorithm at university of Cambridge. He was is inspired by behavior of fireflies [29], [34]. FA can be described into three characteristics [35]. The first, two fireflies are attracted by each other regardless of their sex because all fireflies are unisex. The second, attractiveness is proportional with their brightness, of which the brighter firefly will attract the firefly with less bright. The third, the objective function is the brightness of a firefly. In minimizing problem, the brightness firefly has less objective function. Mathematically, the attractiveness can be shown in eq. (7) as follows:

$$
\beta(r)=\beta_{0} e^{\left(-\gamma r^{m}\right)} \quad m \geq 1
$$




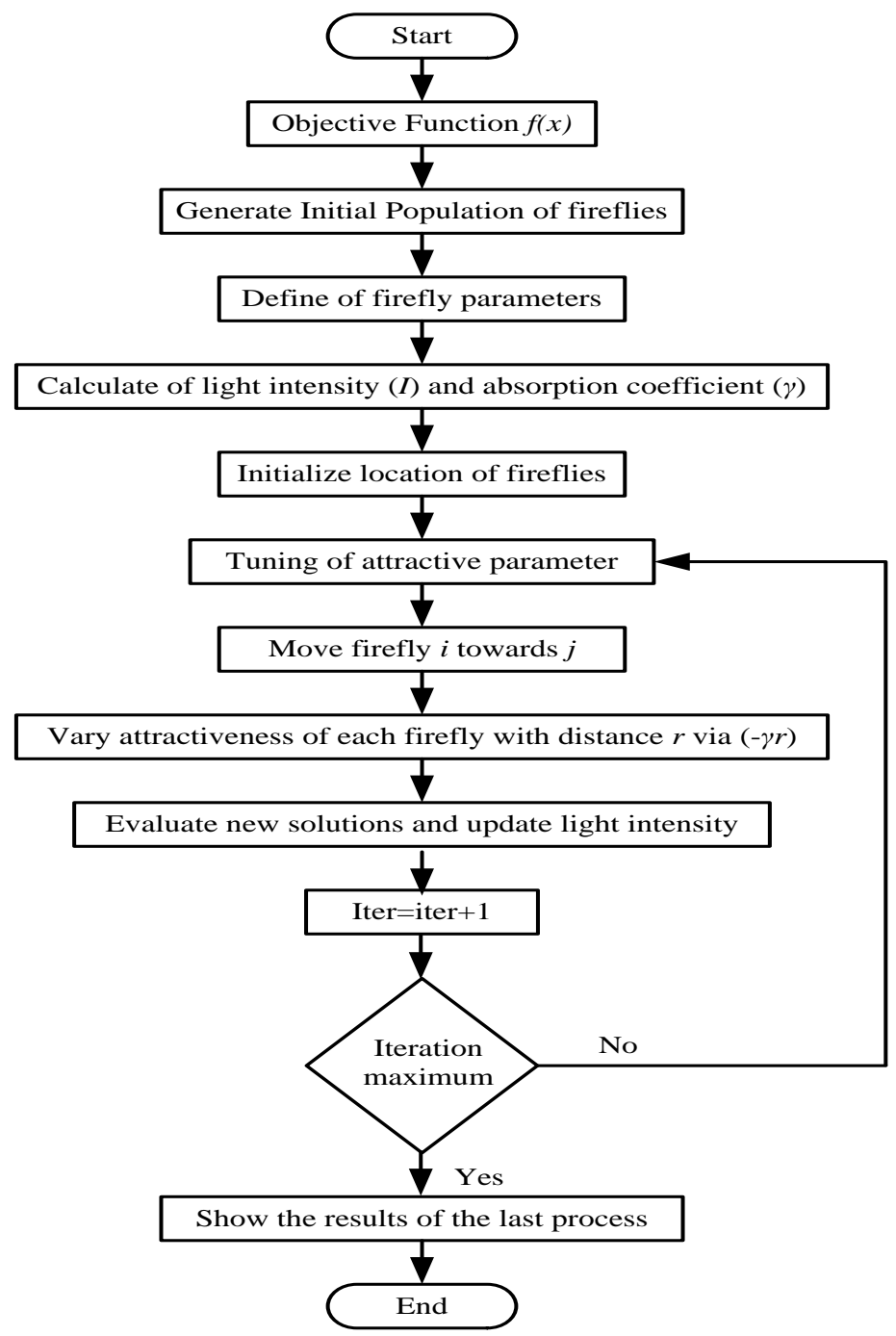

Figure 1. Flowchart of firefly Algorithm

Where, the distance between two fireflies $i$ and $j$ is calculated by Cartesian distance is $r$, which is showed in eq. (8) as follows:

$$
\begin{aligned}
& r_{i j}=\left\|X_{j}-X_{i}\right\|=\sqrt{\sum_{m=1}^{k}\left(x_{j, m}-x_{i, m}\right)^{2}} \\
& X_{j}=\left[x_{j, 1}, x_{j, 2}, x_{j, 3} \ldots, x_{j, k}\right] \\
& X_{i}=\left[x_{i, 1}, x_{i, 2}, x_{i, 3} \ldots, x_{i, k}\right]
\end{aligned}
$$

The movement of a firefly with less brightness $\left(X_{i}\right)$ attracts to another the brighter firefly $\left(X_{j}\right)$ is determined by:

$$
X_{i}=X_{i}+\beta_{0} e^{\left(-\gamma r^{m}\right)}\left(X_{j}-X_{i}\right)+\alpha \varepsilon_{i}
$$


Where, $\varepsilon_{\mathrm{j}}$ is a random value of Gaussian distribution. The eq. (9), demonstrates that the movements of fireflies consist of three terms. The first, it describes the current position of the $i$ th firefly. The second, the movement of a firefly with less brightness attracts to another brighter firefly. The third, it describe the random movement of the firefly with value from interval $[0,1]$. The FA can be shown in figure 1 .

\section{MFA}

This algorithm was proposed by M. H. Sulaiman et al [32], [36]. The modified FA is used to eliminates weakness of FA by improving randomness of the fireflies because it influences the fireflies in exploration of optimal solution. The MFA reduces the randomness of fireflies by using the randomization parameter $\alpha$. In the FA process, the simple mutation of the randomization parameter $\alpha$ corresponds changing to the changing of iteration. In every iteration, the randomization parameter $\alpha$ is reduced 0.001 . The MFA, then, quickly gives assistance to obtain convergence. The MFA are shown in figure 2.

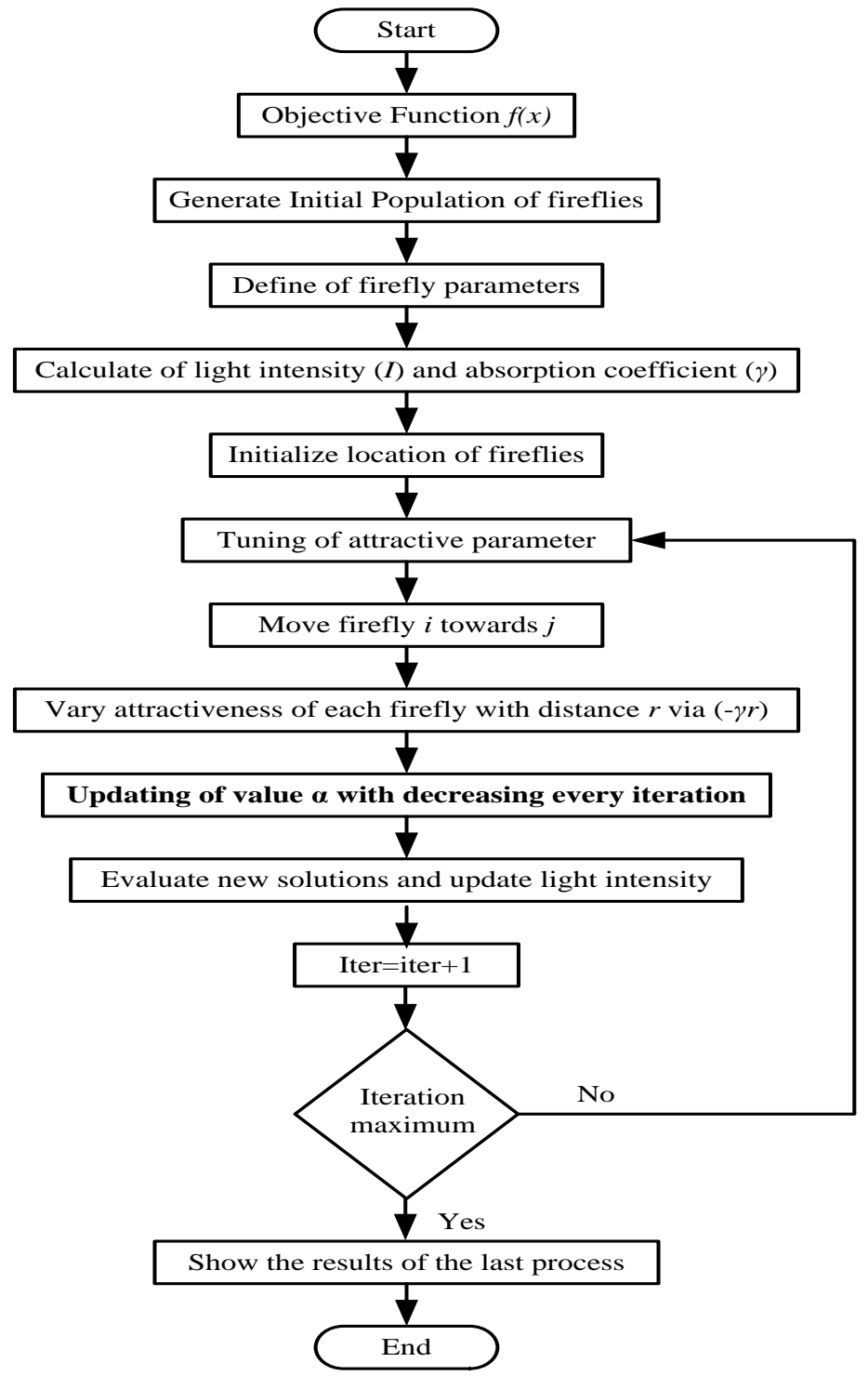

Figure 2. Flowchart of modified firefly algorithm 


\section{Simulation Results and Analysis}

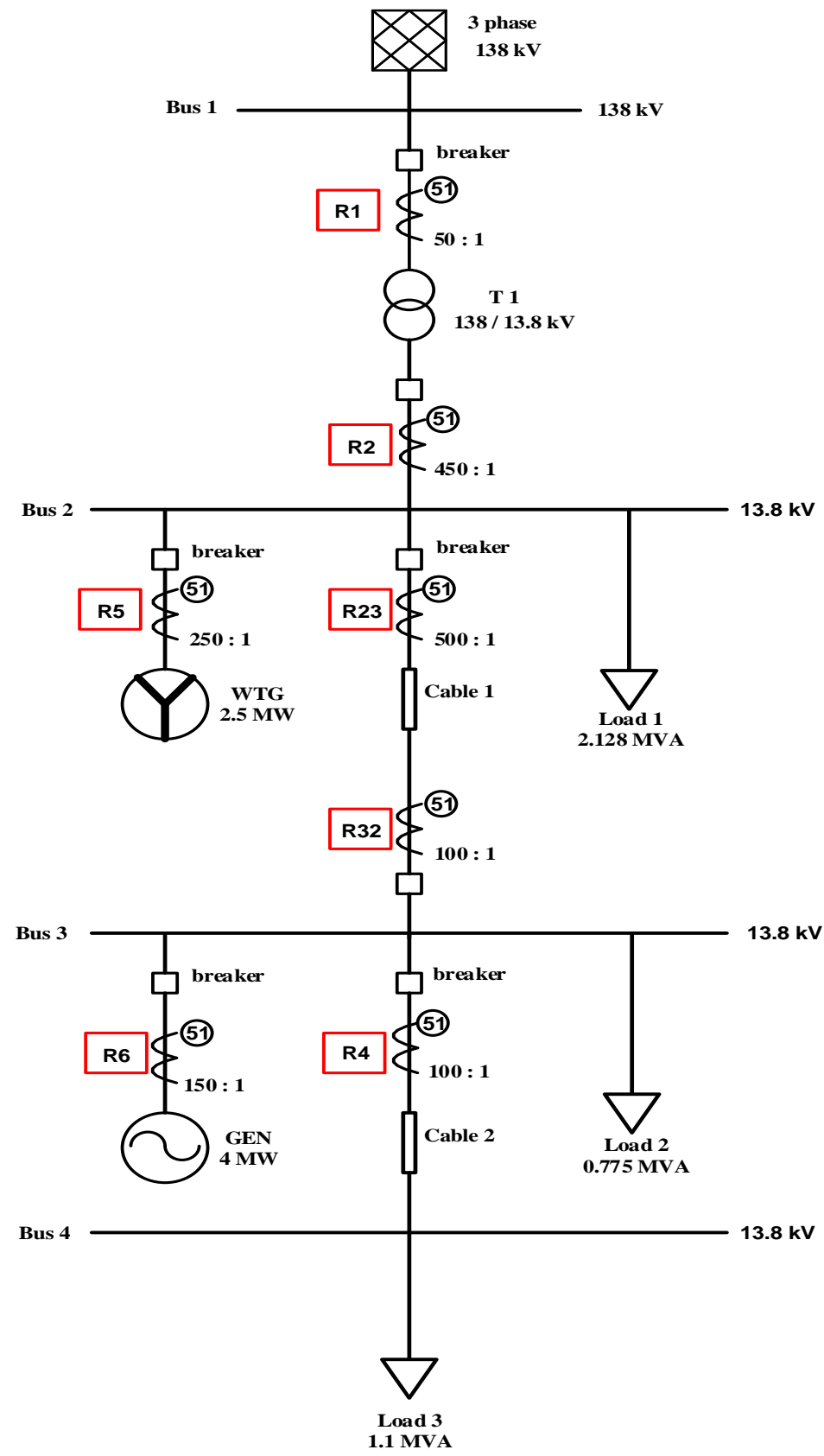

Figure 3. System of radial network with DG

The proposed algorithm is simulated in the radial network, which consist of grid, wind turbine generator (WTG), generator, transformer138/13.8 kV, 4 bus systems and 6 OCRs shown in the figure 3. The incoming power from grid is 3 phase $138 \mathrm{kV}$, of which the transformer reduces the voltage into $13.8 \mathrm{kV}$. DG with capacity of $2.5 \mathrm{MW}$ is installed in the bus of $2 \mathrm{~A}$. A generator with capacity of $4 \mathrm{MW}$ is installed in the bus of 3 . A wind turbine with capacity of $2.5 \mathrm{MW}$ is installed in the bus 2 . The system is equipped with 3 loads. In the bus 2 , load 1 is installed with capacity of 2.218 MVA. Load 2 is installed with capacity of 0.775 
MVA in the bus 3. Load 3 is installed with capacity of 1.1 MVA in the bus 4 . The proposed algorithm is performed over four different test cases which change the systems under presence of DG affecting settings of protection coordination. In each case, the results of proposed algorithm are compared with FA and conventional method. In the figure 4 shows fault current in four different condition systems for three phase fault at the every bus. The four different condition systems are described in the radial network as follows:

Case 1: Optimal coordination of OCRs with conditions of grid, generator and WTG are active.

Case 2: Optimal coordination of OCRs with conditions of grid and generator are active where as WTG is off.

Case 3: Optimal coordination of OCRs with conditions of only grid is active.

Case 4: Optimal coordination of OCRs with conditions of grid is off whereas generator and WTG are active.

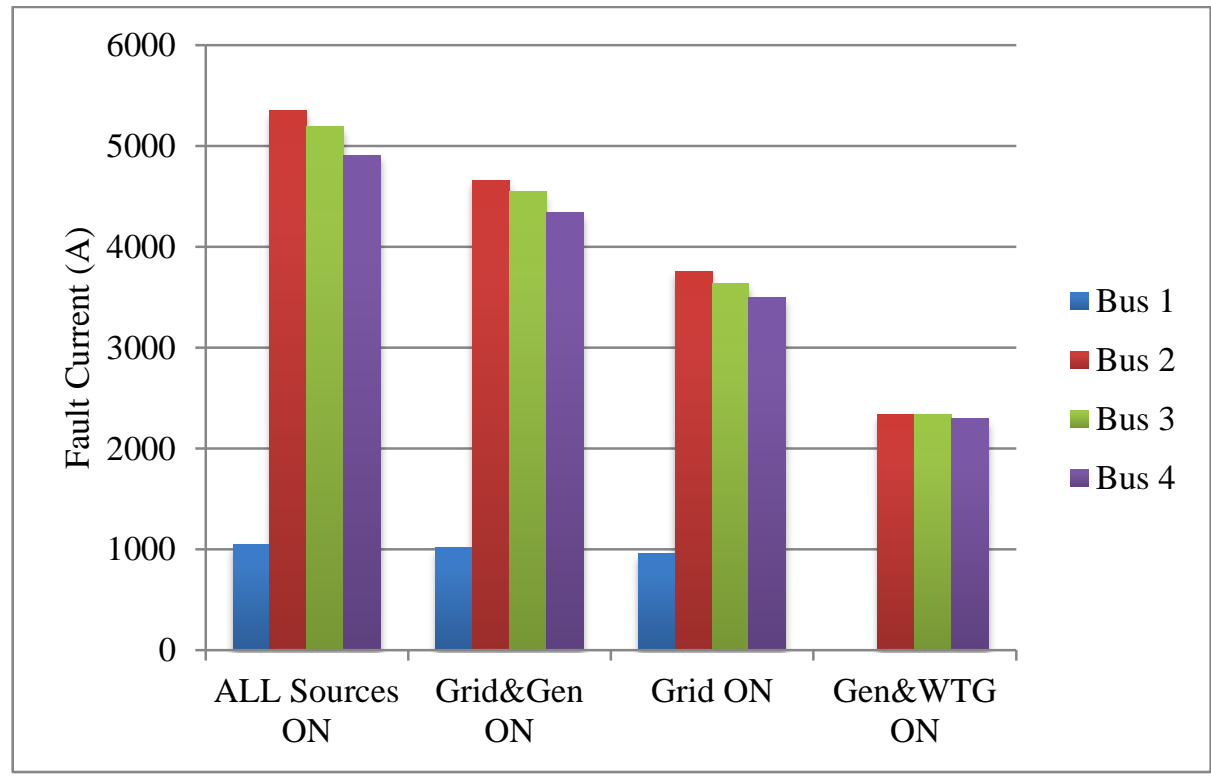

Figure 4. Fault current in four different condition systems for three phase fault at the every bus

\section{A. Case 1}

In the case 1, the proposed algorithm is applied in the conditions of grid, generator and WTG are active of which this system has the biggest fault current among the other cases. The FA is implemented for comparing the proposed algorithm. For a fault at bus 4, OCR R4 represents the primary relay and the other relays as the backup relays. In the table 1, the results demonstrate that optimal coordination using the proposed algorithm has lower fault than FA in the case 1 , which refers to the values of $3.0528 \mathrm{~s}$ and $5.1253 \mathrm{~s}$, respectively. The overall reduction of the proposed algorithm for all relays is $40.44 \%$ compared with FA. It shows that coordination protection using MFA in the case 1 is more optimal than FA and the MFA reduces significantly the operating times of FA. In the figure 5, the proposed algorithm with updating of $\alpha$ has faster convergence than FA. The value of $\alpha$ will affect the accuracy of optimization due to large movements of randomly fireflies produce movement is not leading to the desired point or not optimal. By reducing the value of $\alpha$ will minimize the movement of fireflies, and affecting an increase in the speed of convergence and accuracy of the optimal value. In figure 6 , shows that the relay operates in the order of primary and backup relay operations for each location of the fault so that the fault current can be isolated using relays optimum operating time. The results show that the proposed algorithm can ensure the reliability and speed of operation of the relay. 
Anang Tjahjono, et al.

Table 1. The results of optimal coordination of OCRs using the proposed algorithm in the case 1

\begin{tabular}{|c|c|c|c|c|}
\hline \multirow{2}{*}{ Relay } & \multicolumn{2}{|c|}{ FA } & \multicolumn{2}{c|}{ MFA } \\
\cline { 2 - 5 } & PS(s) & TMS(s) & PS(s) & TMS(s) \\
\hline R4 & 0.968 & 0.196 & 0.967 & 0.105 \\
\hline R32 & 0.825 & 0.328 & 0.824 & 0.216 \\
\hline R2 & 0.977 & 0.42 & 0.976 & 0.206 \\
\hline R1 & 0.882 & 0.494 & 0.879 & 0.35 \\
\hline R5 & 0.862 & 0.444 & 0.861 & 0.305 \\
\hline Objective function & \multicolumn{2}{|c|}{$5.1253 \mathrm{~s}$} & \multicolumn{2}{c}{$3.0528 \mathrm{~s}$} \\
\hline
\end{tabular}

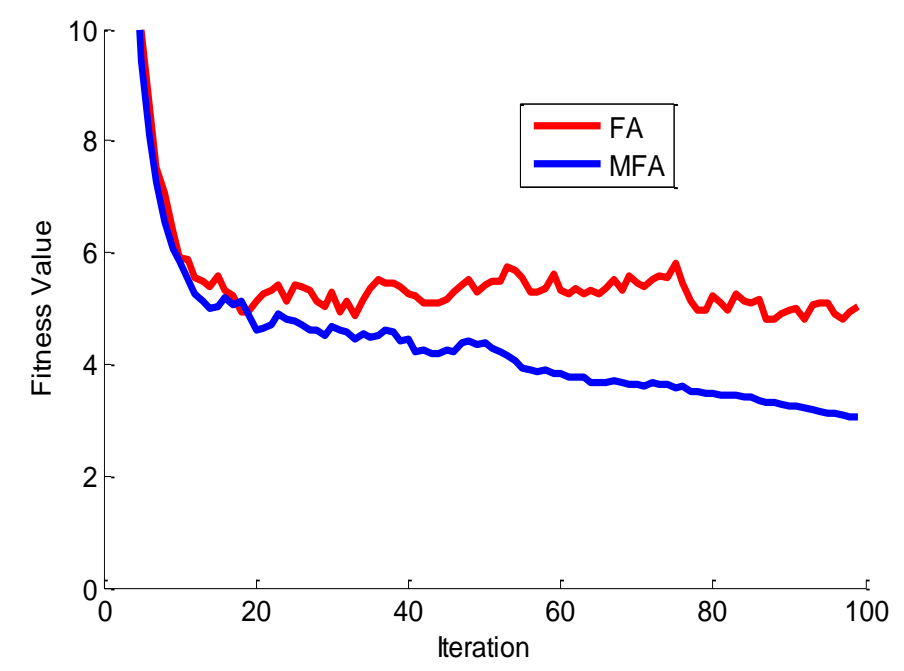

Figure 5. Convergence of the proposed algorithm and FA for 50 initial fireflies in the case 1 


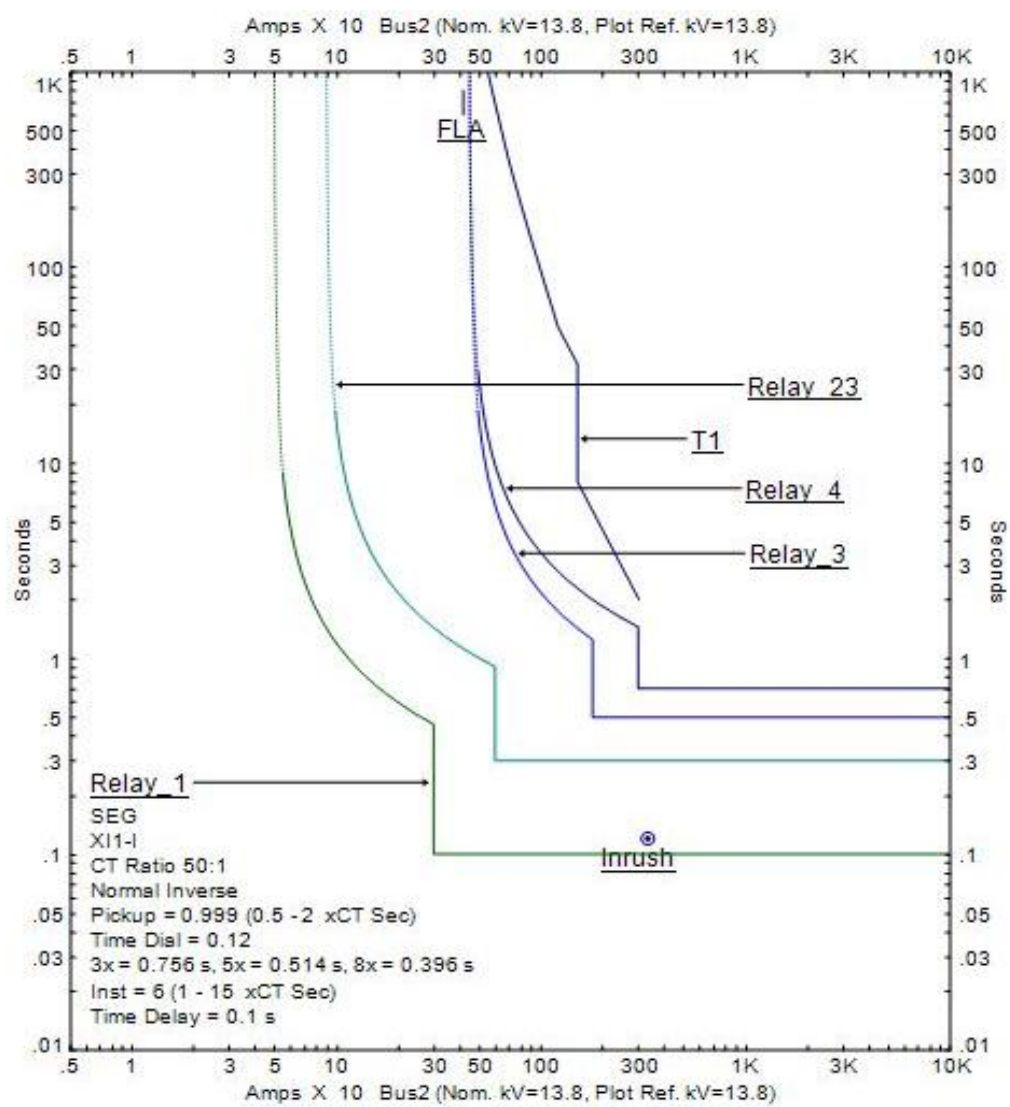

(a)

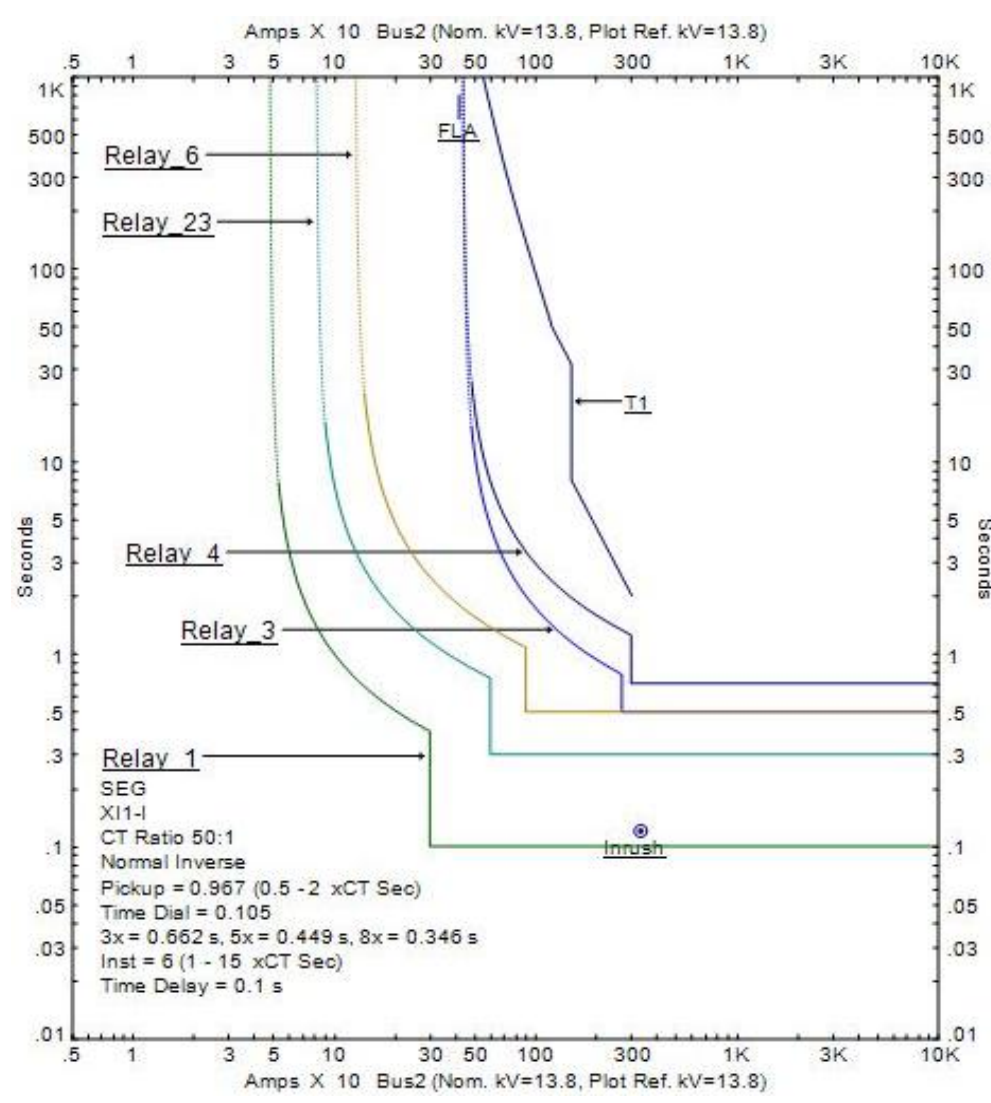

(b)

Figure 6. (a) The optimal OCRs coordination using the conventional method in the case 1, (b) The proposed coordination protection scheme in the case 1 


\section{B. Case 2}

In the case 2, the proposed algorithm is implemented in the system without operating WTG. This system has fault current lower than fault current in the case 1. For a fault at bus 4, OCR $\mathrm{R} 4$ represents the primary relay and the other relays as the backup relays. In the table 2 , the results demonstrate that fault in the optimal coordination using the proposed algorithm is lower than the fault in FA in the case 2. The fault values refer to $2.5623 \mathrm{~s}$ and $4.0496 \mathrm{~s}$, respectively. The overall fault reduction of the proposed algorithm for all relays is $36.73 \%$ when it is compared with FA. It shows that coordination protection using MFA in the case 2 is more optimal than FA the MFA significantly reduces the operating times of FA. In the figure 7, the proposed algorithm with updating of $\alpha$ has faster convergence than FA. The value of $\alpha$ affect the accuracy of optimization, because the movement of a large randomized fireflies produce a movement that does not lead to the desired point or not optimal. By reducing the value of $\alpha$ will minimize the movement of fireflies, thereby increasing the speed of convergence and accuracy of the optimal value. In figure 8 , shows that the relay operates in the order of primary and backup relay operations for each location of the fault so that the fault current can be isolated using relays optimum operating time. The results show that the proposed algorithm can ensure the reliability and speed of operation of the relay.

Table 2. The results of optimal coordination of OCRs using the proposed algorithm in the case 2

\begin{tabular}{|c|c|c|c|c|}
\hline & \multicolumn{2}{|c|}{ FA } & \multicolumn{2}{c|}{ MFA } \\
\hline Relay & PS(s) & TMS(s) & PS(s) & TMS(s) \\
\hline R4 & 0.970 & 0.276 & 0.967 & 0.107 \\
\hline R32 & 0.826 & 0.406 & 0.824 & 0.216 \\
\hline R2 & 0.977 & 0.383 & 0.976 & 0.196 \\
\hline R1 & 0.882 & 0.522 & 0.879 & 0.356 \\
\hline Objective Function & \multicolumn{2}{|c|}{$4.0496 \mathrm{~s}$} & \multicolumn{2}{c|}{$2.5623 \mathrm{~s}$} \\
\hline
\end{tabular}

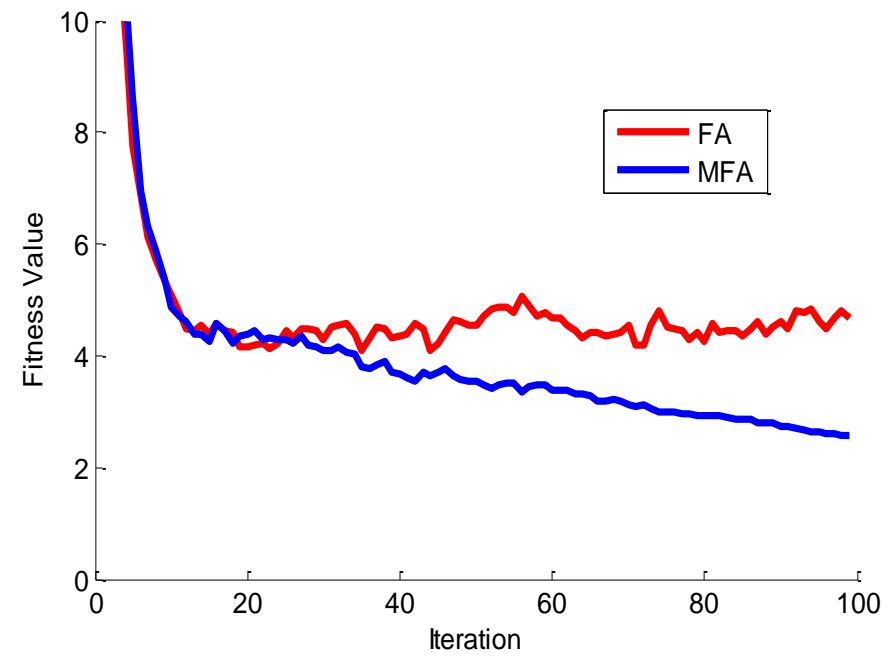

Figure 7. Convergence of the proposed algorithm and FA for 50 initial fireflies in the case 2 


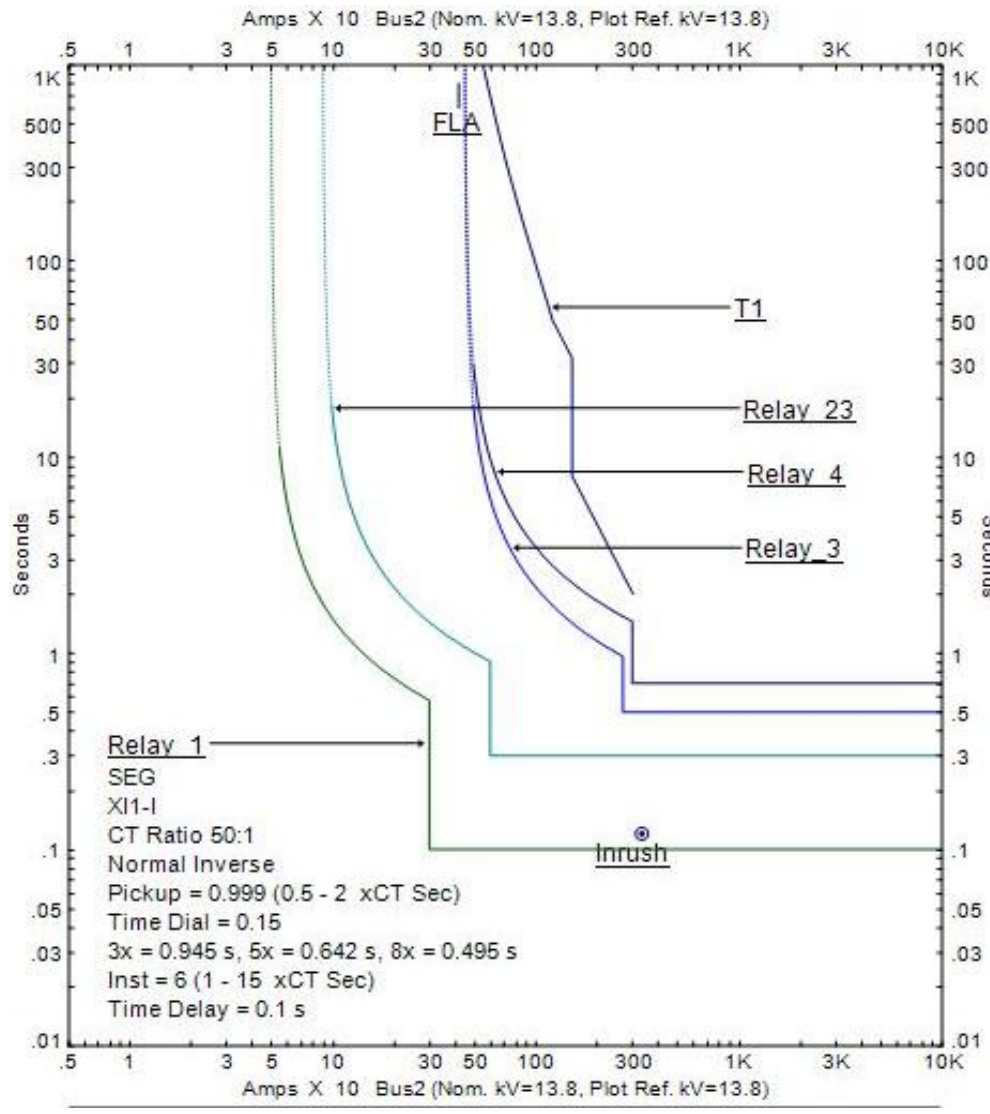

(a)

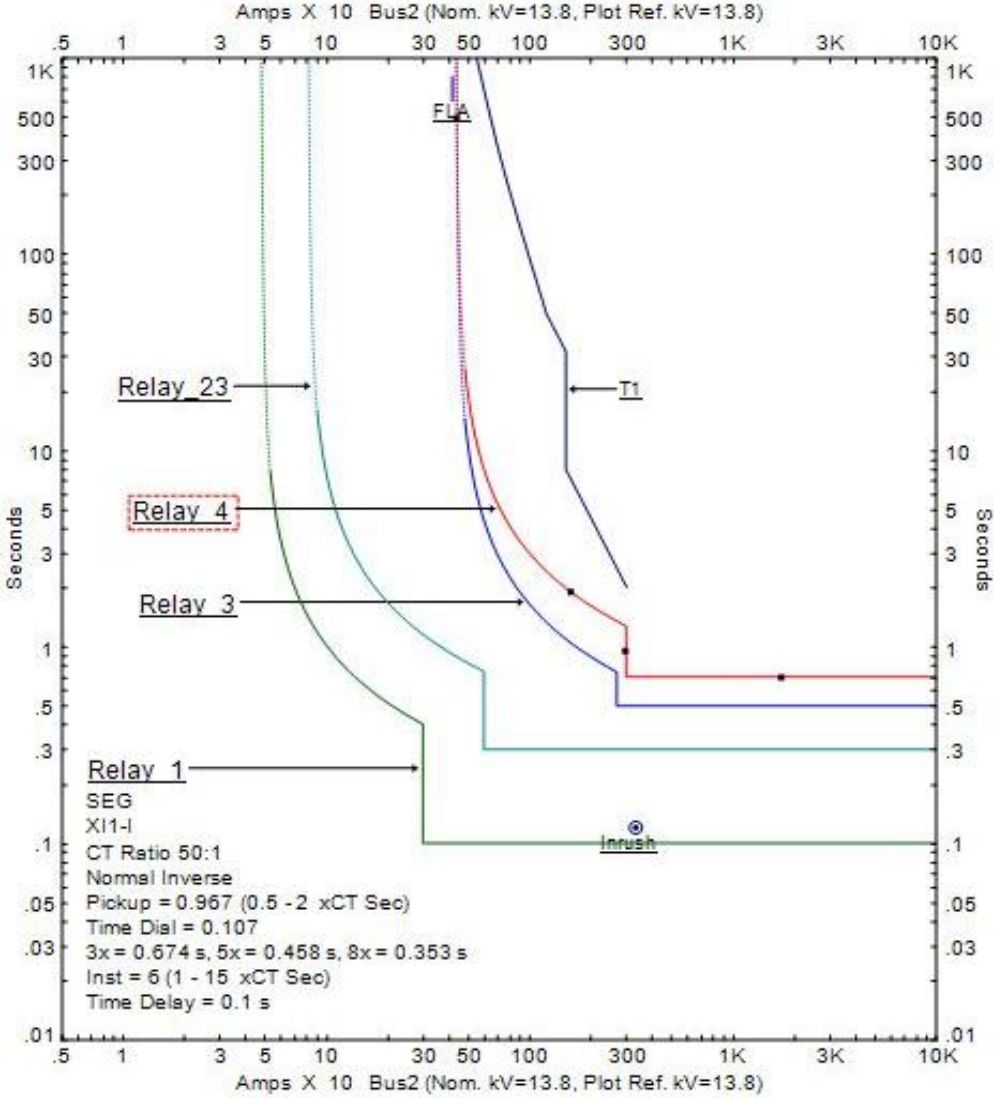

(b)

Figure 8. (a) The optimal OCRs coordination using the conventional method in the case 2, (b) The proposed coordination protection scheme in the case 2 


\section{Case 3}

In the case 3, the proposed algorithm is implemented in the system with grid whereas generator and WTG not operated. For a fault at bus 4, OCR R4 represents the primary relay and the other relays as the backup relays. In the table 3, the results demonstrate that optimal coordination using the proposed algorithm has lower fault than the FA operation in the case 3, of which the values refer to $2.0805 \mathrm{~s}$ and $3.2166 \mathrm{~s}$, respectively. The overall reduction of the proposed algorithm for all relays is $35.31 \%$ compared with FA. It shows that coordination protection using MFA in the case 3 is more optimal than the use of FA and reduces significantly the operating times of FA. In the figure 9, the proposed algorithm with updating of $\alpha$ has faster convergence than the times in FA. The value of $\alpha$ affect the accuracy of optimization due to large movements of randomly fireflies produce movement is not leading to the desired point or not optimal. By reducing the value of $\alpha$ will minimize the movement of fireflies, and affecting an increase in the speed of convergence and accuracy of the optimal value. In figure 10, shows that the relay operates in the order of primary and backup relay operations for each location of the fault so that the fault current can be isolated using relays optimum operating time. The results show that the proposed algorithm can ensure the reliability and speed of operation of the relay.

Table 3. The results of optimal coordination of OCRs using the proposed algorithm in the case 3

\begin{tabular}{|c|c|c|c|c|}
\hline & \multicolumn{2}{|c|}{ FA } & \multicolumn{2}{c|}{ MFA } \\
\hline Relay & PS(s) & TMS(s) & PS(s) & TMS(s) \\
\hline R4 & 0.968 & 0.277 & 0.967 & 0.105 \\
\hline R32 & 0.825 & 0.385 & 0.824 & 0.201 \\
\hline R2 & 0.977 & 0.391 & 0.976 & 0.181 \\
\hline R1 & 0.882 & 0.554 & 0.879 & 0.352 \\
\hline Objective Function & \multicolumn{3}{|c|}{$3.2166 \mathrm{~s}$} & \multicolumn{2}{c|}{$2.0805 \mathrm{~s}$} \\
\hline
\end{tabular}

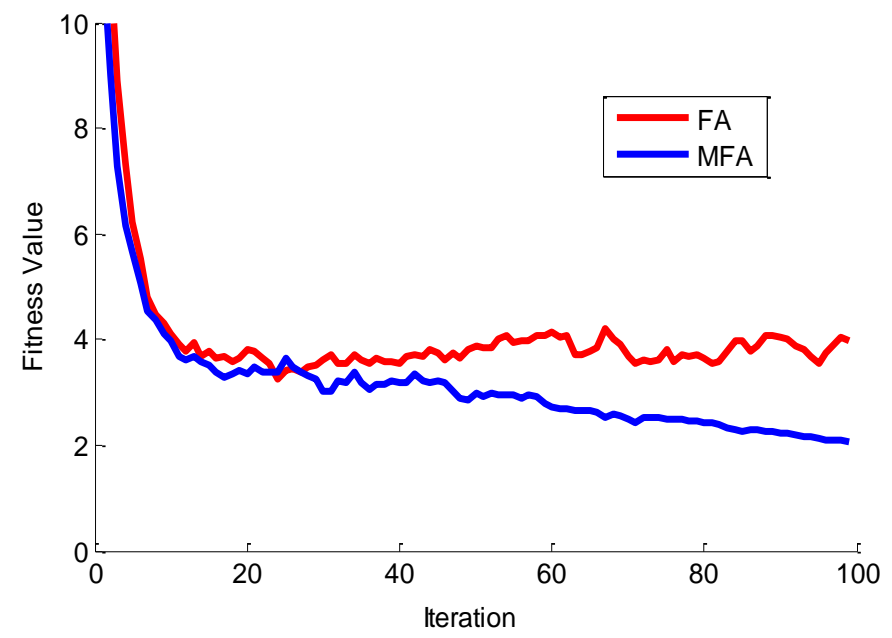

Figure 9. Convergence of the proposed algorithm and FA for 50 initial fireflies in the case 3 


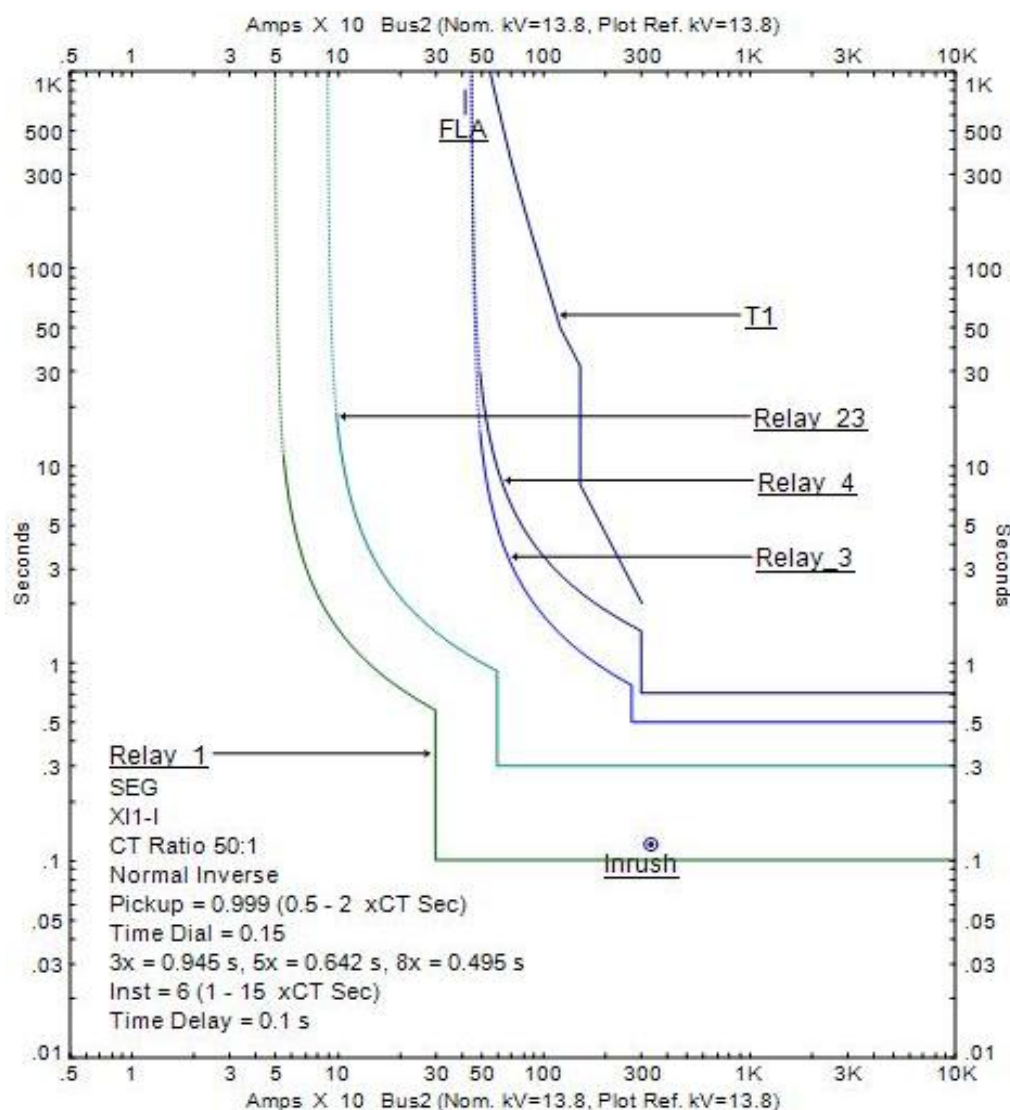

(a)

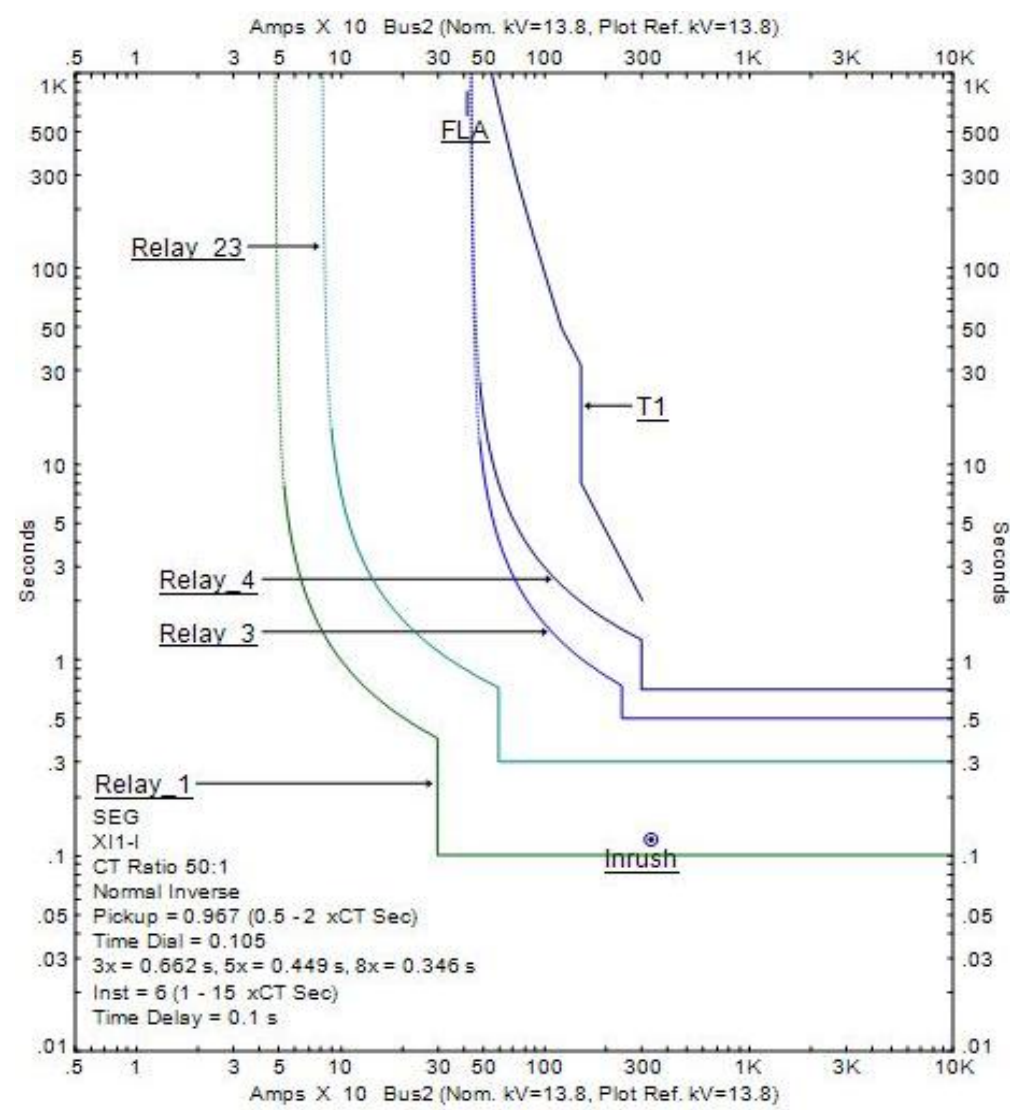

(b)

Figure 10. (a) The optimal OCRs coordination using the conventional method in the case 3, (b) The proposed coordination protection scheme in the case 3 


\section{Case 4}

In the case 4, the proposed algorithm is implemented in the system without grid. This system has the fault current that is the least of the others case. For a fault at bus 4, OCR R4 represents as the primary relay and the other relays as the backup relays. In the table 4 , the results demonstrate that the fault in optimal coordination using the proposed algorithm is lower than the fault in FA in the case 4, which refers the values of $2.1091 \mathrm{~s}$ and $3.5764 \mathrm{~s}$, respectively. The overall fault reduction of the proposed algorithm for all relays is $41.03 \%$ compared with FA. It shows that coordination protection using MFA in the case 4 is more optimal than the use of FA and the FMA reduces significantly the operating times of FA. In the figure 11, the proposed algorithm with updating of $\alpha$ has faster convergence than the time with FA. The value of $\alpha$ affects the accuracy of optimization due to the movement of a large randomized firefly produce the firefly movement not towards the desired point or not optimal. The value of $\alpha$ affect the accuracy of optimization, because the movement of a large randomized fireflies produce a movement that does not lead to the desired point or not optimal. By reducing the value of $\alpha$ will minimize the movement of fireflies, thereby increasing the speed of convergence and accuracy of the optimal value. In figure 12, shows that the relay operates in the order of primary and backup relay operations for each location of the fault so that the fault current can be isolated using relays optimum operating time. The results show that the proposed algorithm can ensure the reliability and speed of operation of the relay.

Table 4. The results of optimal coordination of OCRs using the proposed algorithm in the case 4

\begin{tabular}{|l|l|l|l|l|}
\hline & \multicolumn{3}{|l}{ FA } & MFA \\
\hline Relay & PS(s) & TMS(s) & PS(s) & TMS(s) \\
\hline R4 & 0.970 & 0.293 & 0.967 & 0.106 \\
\hline R23 & 0.936 & 0.317 & 0.935 & 0.181 \\
\hline R6 & 0.828 & 0.364 & 0.827 & 0.207 \\
\hline Objective Function & $3.5764 \mathrm{~s}$ & $2.1091 \mathrm{~s}$ \\
\hline
\end{tabular}

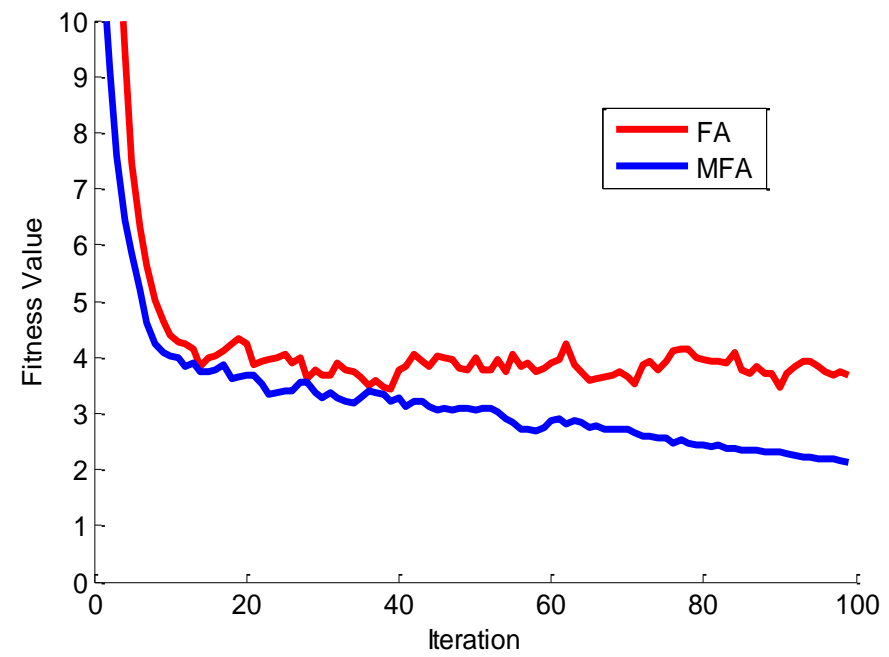

Figure 11. Convergence of the proposed algorithm and FA for 50 initial fireflies in the case 4 


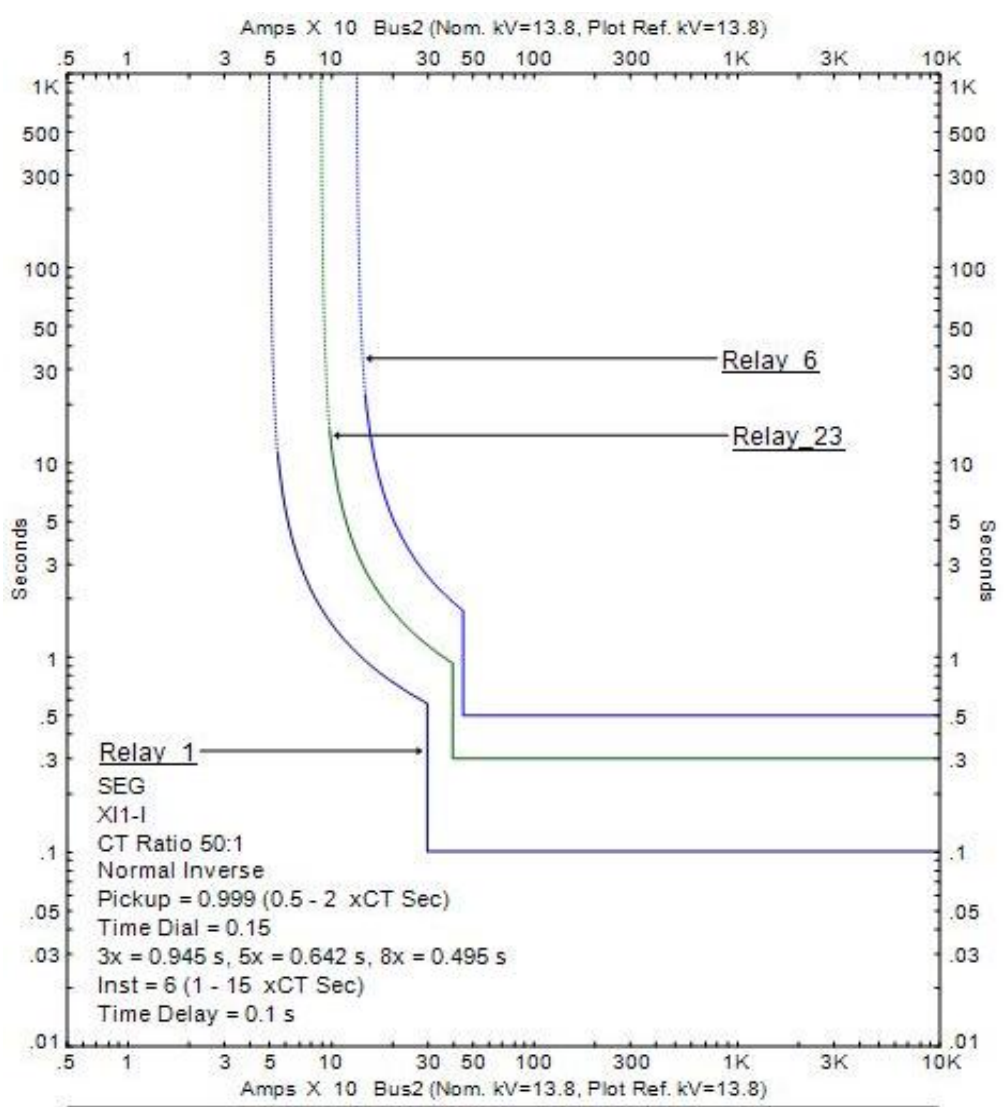

(a)

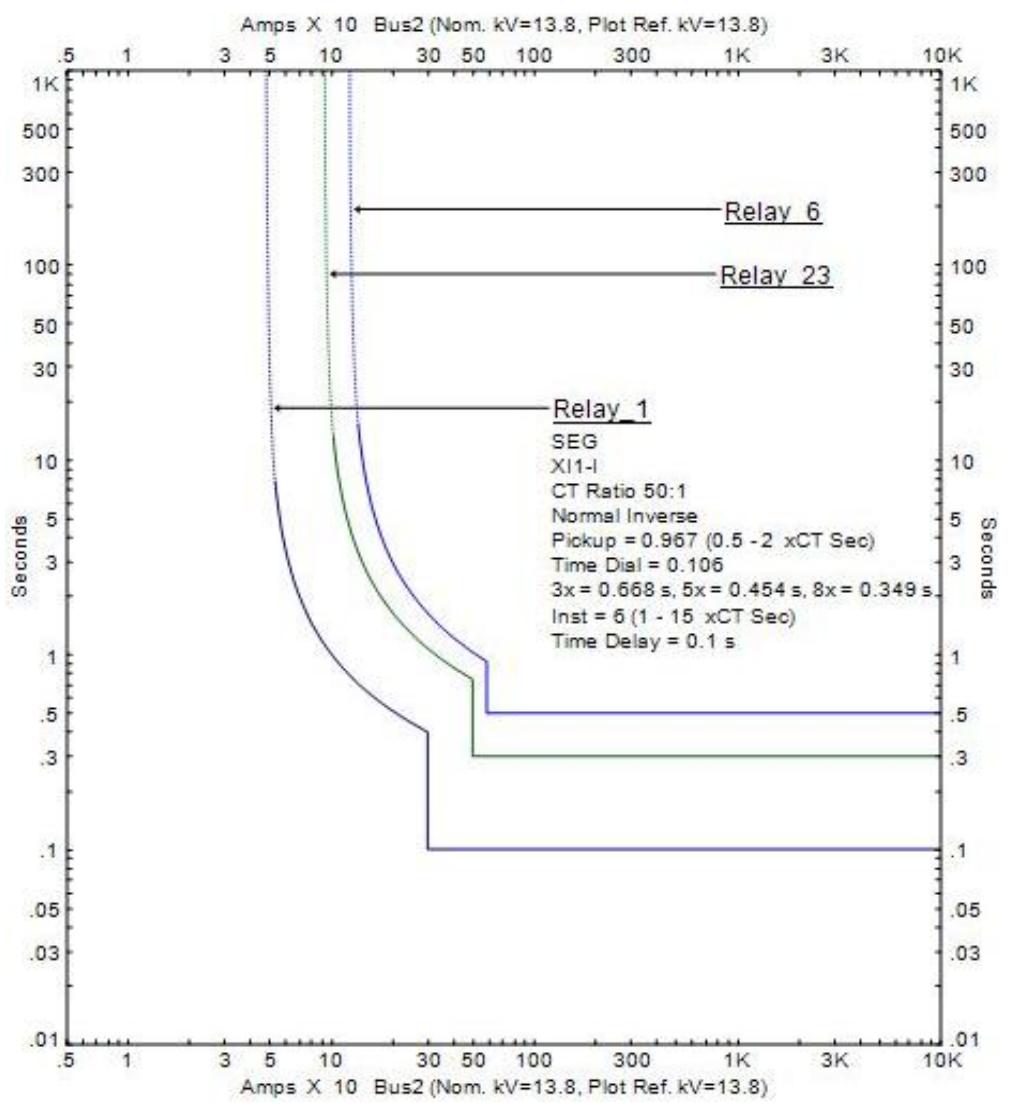

(b)

Figure 12. (a) The optimal OCRs coordination using the conventional method in the case 4 ,

(b) The proposed coordination protection scheme in the case 4 
Table 5. The results of optimal coordination of OCRs using conventional, FA and the proposed algorithm in the all case

\begin{tabular}{|c|c|c|c|c|c|}
\hline System & Relay & Fault Current (A) & Conventional (s) & $\begin{array}{c}\text { Firefly } \\
\text { Algorithm (s) }\end{array}$ & $\begin{array}{l}\text { The Proposed } \\
\text { Algorithm (s) }\end{array}$ \\
\hline \multirow{5}{*}{ Case 1} & $\mathrm{R} 1$ & 300 & 0.46 & 0.738 & 0.395 \\
\hline & $\mathrm{R} 32$ & 600 & 0.905 & 1.134 & 0.746 \\
\hline & R3 & 2700 & 0.959 & 1.452 & 0.779 \\
\hline & $\mathrm{R} 4$ & 300 & 1.448 & 1.454 & 1.251 \\
\hline & R6 & 900 & 1.267 & 1.57 & 1.078 \\
\hline \multirow{4}{*}{ Case 2} & $\mathrm{R} 1$ & 300 & 0.576 & 0.738 & 0.403 \\
\hline & $\mathrm{R} 32$ & 600 & 0.905 & 1.405 & 0.746 \\
\hline & R3 & 2700 & 0.959 & 1.45 & 0.742 \\
\hline & $\mathrm{R} 4$ & 300 & 1.448 & 1.869 & 1.272 \\
\hline \multirow{4}{*}{ Case 3} & $\mathrm{R} 1$ & 300 & 0.576 & 1.043 & 0.395 \\
\hline & $\mathrm{R} 32$ & 600 & 0.905 & 1.328 & 0.715 \\
\hline & R3 & 1800 & 0.996 & 1.914 & 0.885 \\
\hline & $\mathrm{R} 4$ & 300 & 1.448 & 1.984 & 1.258 \\
\hline \multirow{3}{*}{ Case 4} & $\mathrm{R} 1$ & 300 & 0.576 & 1.105 & 0.399 \\
\hline & R32 & 592 & 0.729 & 1.181 & 0.674 \\
\hline & R6 & 596.5 & 1.392 & 1.59 & 0.908 \\
\hline
\end{tabular}

\section{E. The Proposed Coordination Protection Scheme Versus Conventional Scheme}

The proposed algorithm is compared with conventional method because of ensuring reliability and speed of relay operation for isolating the faulted area and evaluating the performance of the proposed algorithm. In the table 5, the results demonstrate that all relays in the proposed algorithm have a reduction in the relay operating time with all relays in the conventional method. Therefore, the proposed algorithm for protection coordination can reduce significantly the overall sum of relay operating times compared with conventional method in the radial systems with DG, which can reduce the mechanical or electrical stress in the primary electrical equipment. The optimization results in each case are implemented in networks in real terms by compiling a data base and operating the table lookup method. The source conditions as input lookup table are used to determine the value of TMS and PS each relay.

After successfully getting the optimal value of each relay, it is necessary to conduct further research to establish coordination with many relays using optimization results have been obtained, and supported by algorithms and communication protocols to establish a centralized coordination or autonomously.

\section{Conclusion}

In this paper, a proposed method is implemented as the optimal coordination of OCRs in the radial network under presence of DG. The operating times of the primary and backup OCRs are minimized by the proposed method to obtain the values of TMS and PS. The proposed algorithm is implemented over four different test cases. The proposed algorithm improves the performance of FA with updating of $\alpha$ The obtained results show that the proposed algorithm for protection coordination can reduce significantly compared with the use of FA, of which the overall reduction for all cases with operating time is $38.38 \%$. For the 
convergence rate, the obtained result show that the proposed method is faster than the FA convergence in finding the global optimum.

\section{References}

[1]. M.H. Hussain, S.R.A. Rahim, I. Musirin, "Optimal Ovecurrent Relay Coordination: A review", Malaysia Technical Universities Conference on Engineering \& Technology, MUCET 2012

[2]. C.R. Chen, C.H. Lee, C.J. Chang, "Optimal Overcurrent Relay Coordination in Power Distribution System Using a New Approach", Electrical Power and Energy Systems 2013; 24:217-222

[3]. IEEE Standard Inverse-Time Characteristic Equations for OCRs, IEEE Std. C37.1121996

[4]. A. Tjahjono, A. Priyadi, M.H. Purnomo, M. Pujiantara, "Overcurrent Relay Curve Modeling Using Adaptive Neuro Fuzzy Inference System”, IEEE Makassar International Conference on Electrical Engineering and Informatics, 2014

[5]. A. Tjahjono, D.O. Anggriawan, A. Priyadi, M.H. Purnomo, M. Pujiantara, "Overcurrent Relay Curve Modeling and Its Application in the Industrial Power Systems Using Adaptive Neuro Fuzzy Inference System", IEEE International Conference on Computational Intelligence and Virtual Environments for Measurement Systems and Applications, 2015

[6]. A. Tjahjono, D.O. Anggriawan, A. Priyadi, M. Pujiantara, M.H. Purnomo, "Digital Overcurrent Relay with Conventional Curve Modeling Using Levenberg Marquardt Backpropagation", IEEE International Seminar on Intelligent and Its Applications, 201

[7]. F. Razavi, H. A. Abyaneh, M. Al-Dabbagh, R. Mohammadi, H. Torkaman, "A New Comprehensive Genetic Algorithm Method for Optimal Ovecurrent Relays Coordination", Electric Power Systems Research 2008; 78:713-720

[8]. R. Mohammadi, H. A. Abyaneh, F. Razavi, M. Al-Dabbagh, S.H.H. Sadeghi, "Optimal Relays Coordination Efficient Method in Interconnected Power Systems", Journal of Electrical Engineering, Vol. 61, No. 2, pp. 75-83, 2010

[9]. S. Conti, "Analysis of Distribution Network Protection Issues in Presence of Dispersed Generation", Electrical Power Systems Research 2009; 79: 49-56

[10]. C.J. Mozina, "Impact of Smart Grids and Green Power Generation on Distribution Systems", IEEE Trans. Indus. App. Vol. 49, No. 3, Jun. 2013

[11]. K. Tuitemwong, S. Premrudeepreechacharn, "Expert System for Protection Coordination of Distribution System with Distributed Generators", Electrical Power and Energy Systems 2011; 33:466-471

[12]. S. Conti, S. Nicotra, "Procedures for Fault Location and Isolation to Solve Protection Selectivity Problems in MV Distribution Networks with Dispersed Generation", Electrical Power and Energy Systems 2009; 79: 57-64

[13]. S.A. Gopalan, V. Sreeram, H.H.C. Lu, "A Review of Coordination Strategies and Protection Schemes for Microgrids", Renewable and Sustainable Energy Reviews 2014; 32: $222-228$

[14]. H.H. Zeineldin, H.M. Sharaf, D.K. Ibrahim, E.E.A. El-Zahab, "Optimal Protection Coordination for Meshed Distribution Systems With DG Using Dual Setting Directional Over-Current Relays", IEEE Trans. Smart Grid, Vol. 6, No. 1, Jan. 2015

[15]. R. Mohammadi, H.A. Abyaneh, A.M. Rudsari, S. H. Fathi, H. Rastegar, "OCRs Coordination Considering the Priority of Constraints", IEEE Trans. Power Del. Vol. 26, No. 3, Jul. 2013

[16]. H.A. Abyaneh, M. Al-dabbagh, H.K. Karegar, S.H.H. Sadeghi, R.A.J. Khan, "A new Optimal Approach for Coordination of OCRs in Interconnected Power Systems", IEEE Trans. Power Del. Vol. 18, no. 2, Apr. 2003 
[17]. A.S. Noghabi, H.R. Mashhadi, J. Sadeh., "Optimal Coordination of Directional OCRs Considering Different Network Topologies Using Interval Linear Programming”, IEEE Trans. Power Del. Jul. 2010

[18]. A. Mahari, H. Seyedi, “An Analytic Approach for Optimal Coordination of OCRs”, IET Gener. Transm. Distrib., Vol. 7, Iss. 7, pp. 674-680

[19]. P.P. Bedekar, S.R. Bhide, V.S. Kale,"Optimum Time Coordination of OCRs in Distribution System Using Big-M Method”, WSEAS Trans. Power Sys. Iss. 4 Vol. 4, Nov. 2009

[20]. M. Ezzeddine, R. Kaczmarek, “A Novel Method for Optimal Coordination of Directional OCRs Considering their Available Discrete Settings and Several Operation Characteristics", Electric Power Systems Research 2011; 81:1475-1481

[21]. C.W. So, K.K. Li, "Overcurrent Relay Coordination by Evolutionary Programming", Electric Power System Research 2000; 53:83-90

[22]. P.P. Bedekar, S.R. Bhide, "Optimum Coordination of Overcurrent Relay Timing Using Continuous Genetic Algorithm", Expert Systems with Applications 2011; 38:1128611292

[23]. Z. Moravej, F. Adelnia, F. Abbasi, "Optimal Coordination of Directional OCRs Using NSGA-II”, Electric Power Systems Research 2015; 119:228-236

[24]. H.H. Zeineldin, E.F.El-Saadany, M.M.A. Salama, "Optimal Coordination of OCRs Using a Modified Particle Swarm Optimization", Electric Power Systems Research 2006; 76: 988-995

[25]. R. Thangaraj, M. Pant, K. Deep, "Optimal Coordination of OCRs Using Modified Differential Evolution Algorithms", Engineering Applications of Artificial Intelligence 2010; 23:820-829

[26]. M. Singh, B.K. Panigrahi, A.R. Abhyankar, "Optimal Coordination of Directional OCRs Using Teaching Learning-Based Optimization (TLBO) Algorithm”, Electrical Power and Energy Systems 2013;50:33-41

[27]. P.P. Bedekar, S.R. Bhide, "Optimum Coordination of Directional OCRs Using the Hybrid GA-NLP Approach”, IEEE Trans. Power Del, vol. 26, no. 1, Jan. 2011

[28]. T. Amraee, "Coordination of Directional OCRs Using Seeker Algorithm", IEEE Trans. Power Del. Vol. 27, no. 3, Jul. 2012

[29]. S.S. Gokhale, V.S. Kale,"Application of the FA to Optimal Overcurrent Relay Coordination", IEEE International Conference on Optimization of Electrical and Electronic Equipment, 2014

[30]. M.H. Sulaiman, H. Daniyal, M.W. Mustafa, "MFA in Solving Economics Dispatch Problems with Practical Constraints", IEEE International Conference on Power and Energy, 2012

[31]. M. Zellagui, R. Benabid, M. Boudour, A. Chaghi, "Application of FA for Optimal Coordination of Directional Overcurrent Protection Relays in Presence of Series Compensation", Journal of Automation \& Systems Engineering 2014; 8-2:92-107

[32]. M.H. Sulaiman, H. Daniyal, M.W. Mustafa, "MFA in Solving Economic Dispatch Problems with Practical Constraints", IEEE International Conference on Power and Energy, 2012

[33]. A. Conde, E. Vazquez, "Application of a Proposed Overcurrent relay in Radial networks", Electric Power Systems Research 2011; 81:570-579

[34]. X.S. Yang, "FA, Levy Flights and Global Optimization", in Research and Development in Intelligent Systems XXVI, pp. 209-218, Springer, London, UK, 2010

[35]. A.K. Fard, T. Niknam, "Optimal Stochastic Capacitor Placement Problem from the reliability and cost Views Using FA", IET Sci. Meas. Technol., 2014, vol. 8, Iss. 5, pp. 260-269

[36]. S. Goel, V.K. Panchal, "Performance Evaluation of a New MFA", IEEE International Conference on Reliability, Infocom Technologies and Optimization, 2014 


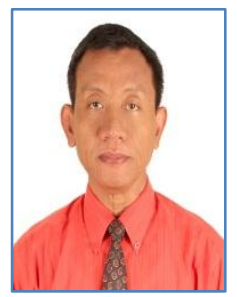

Anang Tjahjono was born in Ponorogo, East Java Province Indonesia on November 19, 1964, this time as a doctoral student at the Institut Teknologi Sepuluh Nopember Surabaya (ITS) Indonesia. Starting in 1990 as a lecturer in Electronic Engineering Polytechnic Institute of Surabaya Indonesia, teaching field of industrial automation, artificial intelligence, as well as microcontroller, experienced as JICA Expert in Rwanda Africa. Research is being done at this time is the field of adaptive protection relay in the distribution system using Artificial Intelligent method, Currently pursuing a doctoral program in ITS. Received a bachelor's degree in 1990 in the course of electronics in ITS, and got a master's degree in control systems in ITS in 1999.

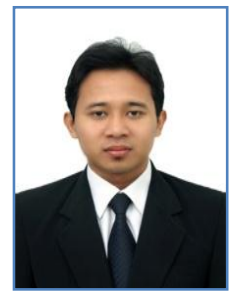

Dimas Okky Anggriawan received the B.E. degree from electrical engineering department, Institut Teknologi Sepuluh Nopember in 2013 and M. Eng degree from electrical engineering department, Institut Teknologi Sepuluh Nopember in 2015. He is currently as lecturer in the Politeknik Elektronika Negeri Surabaya. His research interests include power quality, protection coordination and artificial intelligent

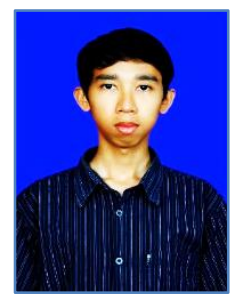

Alfa Kusnal Faizin received the B.E. degree from electrical engineering department, Institut Teknologi Sepuluh Nopember in 2015. He is currently as engineer in the PT. PLN. His research interests include protection coordination and artificial intelligent

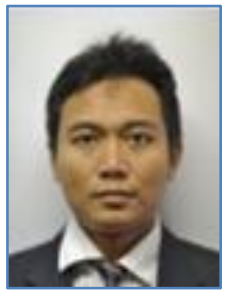

Ardyono Priyadi was born in Nganjuk east java of Indonesia on September 27, 1973. He received his bachelor degree in Electrical Power System Engineering from Institut Teknologi Sepuluh November (ITS), Indonesia in 1997, master and Ph.D. degree in Electrical Power System Engineering from Hiroshima University, Japan in 2008 and 2011. He is currently a lecturer at Electrical Engineering Department, ITS. His research interest is power transient stability, renewable energy, and identification of power systems.

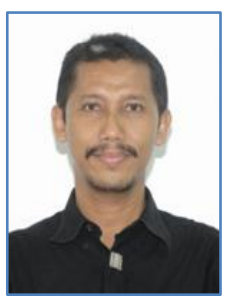

Margo Pujiantara was born in Pasuruan east java of Indonesia on March 18, 1966. He received his bachelor degree in Electrical Power System Engineering from Institut Teknologi Sepuluh November (ITS), Indonesia in 1985, master's degree from Institut Teknologi Bandung (ITB), Indonesia in 1995 and Ph.D. degree from Institut Teknologi Sepuluh November (ITS), Indonesia in 2011. He is currently a lecturer at Electrical Engineering 
Department, ITS. His research interest is renewable energy, protection and identification of power systems

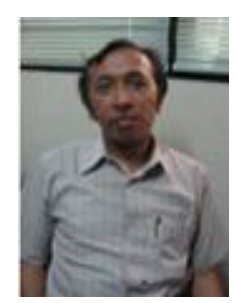

Mauridhi Hery Purnomo was born in Bangkalan east java of Indonesia on September 16, 1958. He received his bachelor's degree from Electrical Engineering Institute Technology Sepuluh November, Surabaya in 1984 and master's degree from Electrical Engineering Osaka city University, Japan in 1989, and Ph.D. degree in Power system from Osaka city University, Japan in 1995. where he is currently an head Laboratory of Instrumentation, Measurement and Power System Identification and a professor of Electrical Engineering Institute Technology Sepuluh November, Surabaya. His research interest is Artificial Intelligent, Neural Network, Image Processing, renewable energy, condition and monitoring system. 